\title{
Influence of plant developmental stage on DNA yield and extractability in MON810 maize
}

\author{
Isabel Taverniers ${ }^{1}$, Laurens De Meyer ${ }^{1}$, Bart Van Droogenbroeck ${ }^{1}$, Kathy Messens ${ }^{2,3}$, Marc De Loose ${ }^{1}$ \\ ${ }^{1}$ Institute for Agricultural and Fisheries Research (ILVO), Technology and Food Science Unit, Burg. Van Gansberghelaan 115, \\ 9820 Merelbeke, Belgium \\ ${ }^{2}$ Department of Applied Biosciences, Faculty of Applied Bioscience Engineering, Ghent University, Valentin Vaerwyckweg 1, \\ 9000 Gent \\ ${ }^{3}$ Department of Molecular Biotechnology, Faculty of Applied Bioscience Engineering, Ghent University, Coupure links 653,9000 \\ Gent \\ email: isabel.taverniers@ilvo.vlaanderen.be
}

\begin{abstract}
The amount and extractability of DNA in different parts of MON810 GM hybrid was studied during different developmental stages. To quantify GM contents, an evaluation was performed of the effect of plant development stage on DNA density. To this end, the evolution of weights, absolute DNA yields, DNA densities and ratios of endosperm and embryo relative to total maize kernel were studied. Sampling at four stages during the growth shows an influence on relative GM quantification based on haploid genome equivalents, due to the specific maize seed composition and differences in DNA extractability from different seed tissues. During plant growth, plant parts with potential GM genes (embryo in kernel and cob on total plant) increase in importance on weight and DNA concentration level, while the endosperm drops in relative importance. Expected \% GM maize values are calculated for a whole field harvest of grain maize.
\end{abstract}

Keywords: co-existence, adventitious presence, labeling threshold, MON810 maize, DNA density, DNA extractability, seed embryo, seed endosperm

\section{Introduction}

Maize is one of the most important crops for food and feed use in our modern society. Since the domestication of this crop between 10000 and 5000 B.C.E. (Piperno et al. 2001), there have been a lot of changes in the genetic structures of the plant to achieve better plant properties (higher yield and nutritional value, improved pest resistance, etc.), mainly by means of conventional breeding. Over the last two decades a great leap forward in the improvement of maize was achieved by means of genetic modification. These types of interventions in the genomic structures of an organism led to concerns about the safety of our food, feed and environment (Devos et al. 2008). After many years of debate, the European Union declared guidelines and directives to regulate the cultivation, commercialization and labeling of genetically modified organisms (GMOs) (EC 2001, 2003 a, b). According to these regulations, food or feed that contains less than $0,9 \%$ of GMO per ingredient does not have to be labeled in case of adventitious presence.

The cultivation of different production types (organic, conventional and genetically modified), also called co-existence, is regulated by Commission Recommendation 2010/C 200/EC (EC 2010), which gives member states the responsibility for developing their own co-existence legislation. Hereby, member states can implement a legislation which takes into account local habits and agricultural practices specific for the region. This recommendation requires member states to compose a legislation which stipulates a set of precautions to be taken in order to prevent adventitious presence of $\mathrm{GMO}$ (s) into non-GM products. In Belgium, the coexistence rules are implemented at regional level by the decree of the Flemish parliament of 3 April 2009 regarding the organization of co-existence of GM crops with conventional and organic crops. According to this decree, the Flemish government described "decisions of the Flemish Government" (i.e. resolutions to implement the decree) for the co-existence of agricultural crops in general and also for the co-existence of different crop production types. These decisions describe crop-specific co-existence regulations for the GM crops relevant for the Flemish agricultural context, i.e. for maize, potato and sugar beet. In order to evaluate the proposed regulation for maize co-existence, practical assessments have been conducted in 2010-2011. 
GM fields can contaminate neighboring crops. The \% GM assessment for a non-GM field, cross-fertilized by GM pollen coming from a neighbor GM field, depends on the distance between the non-GM and the GM field, the topography of the fields, the used sampling strategies, the used type(s) of maize, the amount of maize produced and harvested (Vogler et al. 2010, Njontie et al. 2011, Chaouachi et al. 2013, Devos et al. 2014). In Belgium, maize has two usages: silage maize (63\%), where the whole maize plant is harvested and ground, and grain maize (37\%), result of the harvest of only the cobs (as a whole), or only the grains. The grain maize area can be divided in conventional grain maize, Corn Cob Mix (CCM) and earlage maize. In addition, some biological factors like genetic structures and the DNA extractability from different types of tissue, will have an influence on the final calculated GM percentage (Trifa and Zhang 2004, Papazova et al. 2005, 2006, Zhang et al. 2008). Different development stages can be described during the growth season of a maize plant. Growth patterns are divided into vegetative and reproductive stages. Vegetative stages start at the VE (Emerge) stage and end with the VT (Tasseling) stage. The stages in-between are divided as $V_{(n)}$ stages where $n$ represents the number of visible leaf collars which fluctuate with hybrid and environmental differences. Reproductive stages are divided in six stages $\left(R_{1}\right.$ to $\left.R_{6}\right)$. In these stages kernel characteristics are followed to distinguish different stages (Ransom et al. 2014).

The overall GM percentage can be expressed as a weight or a DNA copy number ratio. In the EU, a number of HGE (Haploid Genome Equivalents) is the \% GM recommended unit for GM quantifications for food and feed (EC 2004). According to this recommended unit, GM quantifications determined as a weight percentage should be converted into a GM copy number percentage (Holst-Jensen et al. 2006). This ratio is influenced by the maize plant structure as well as the specific GM variety. While MON810, the GM line studied here, only contains one inserted construct (one GM gene), other varieties may contain up to 7 newly inserted GM constructs. When we consider a non-GM maize plant, cross-fertilized by GM pollen e.g. from MON810 maize the distribution of the GM genes in the fertilized plant will be as follows. The stalk and leaves do not contain any foreign genes. The maize ear can be divided in a pure maternal fraction and a partially paternal fraction. The maternal fraction contains the husk and the center of the ear. The kernels are partially paternal, they are made out of endosperm (83\%), embryo (11\%), pericarp (5\%) and tip cap (1\%). Endosperms are triploid, containing two maternal polar nuclei and one sperm nucleus. Embryos are diploid (double fertilization in angiosperms), including one haploid maternal nucleus and one haploid paternal nucleus. The pericarp consists out of two maternal nuclei (Lopes and Larkins 1993, Trifa and Zhang 2004, Papazova et al. 2005, 2006).

Between the fertilization of the kernels and the fully mature stage, the kernel undergoes a lot of physical and physiological changes mainly because after pollination, the overall plant energy is invested in the development of the reproductive structures. These changes can be evaluated by changes in weight and DNA content of the different vegetal parts, especially the ratio between parts with paternal genes and parts with merely maternal genes. When a conventional maize kernel is fertilized by a MON810 pollen, the percentage GM DNA of the grain can be calculated at different development stages by this formula:

$$
\text { GM DNA ratio }=1 / 3 F+1 / 2(1-F)=0,5-0,167 F
$$

where $\mathrm{F}$ is the endosperm DNA content between 0 and 1 , relative to the total kernel DNA and 1-F is the embryo DNA content relative to the total kernel DNA. Thus $1 / 3 \mathrm{~F}$ is the GM DNA from the kernel endosperm and 1/2 (1-F) is the GM DNA from the embryo (Zhang et al. 2008).

The objective of this paper is to evaluate some factors that will influence the final calculated GM percentage, for example, genetic structures and DNA extractability from different types of tissue. Papazova et al. (2005) describes a $50 \%$ higher DNA yield for the embryo in comparison with the DNA yield of the endosperm. These deviations have to be taken into account for the correct interpretation of the global field or harvest GM percentage.

The overall aim of this paper is to examine how different plant parts of the maize crop develop in comparison with each other and if samples, taken at different stages during the growth season of maize, are representative for the overall GM percentage obtained after harvesting a whole mature field. 


\section{Materials and methods Sampling and sample preparation}

Seeds of a MON810 GM hybrid (Monsanto) were sown on a 1 ha field on 27 April 2010 at ILVO (Institute of Agricultural and Fisheries Research) test fields situated in Wetteren, Belgium. Between the end of pollination and the harvest, plant samples were taken at four different times (12 August, 31 August, 14 September and 4 October 2010). At each sampling time, plants were selected at random from the middle of the field and cut $50 \mathrm{~mm}$ above the ground surface. This is the average cutting height of a forage harvester. Per individual plant, the weights of the whole plant, the cob and the vegetative part of the plant were determined. Subsequently three kernels were removed from the cob, one from the top, middle and bottom, and the weights of these kernels were determined. At the sampling stages where it was possible to separate the embryo and the endosperm of the kernel, also these individual weights were determined. The vegetative plant parts and the cob were chopped separately by the Robot Coupé CL50 (Robot Coupé belux, BE) and then individually wrapped and frozen at $-80^{\circ} \mathrm{C}$. The grain, endosperms and embryos were frozen at $-80^{\circ} \mathrm{C}$. The next step in the procedure was to dry the material by lyophilizing. After drying, samples; kernels, endosperm and germs were ground with an Retsch MM 400 (Retsch GmbH, DE), for $3 \mathrm{~min}, 30 \mathrm{~s}^{-1}$ frequency, plant tissue and cobs with a Peppink 200 AN hammer mill over a $0.75 \mathrm{~mm}$ sieve (Peppink Mills, NL). The ground samples were stored dry at room temperature.

\section{DNA extraction and DNA yield and quality checks}

DNA was isolated from 20 mg lyophilized material of each sample following the DNeasy Plant Mini Kit (Qiagen Benelux, the Netherlands). The final elution volume was $75 \mu \mathrm{l}$. Extracted DNA (ng $\mu \mathrm{l}^{-1}$ ) was quantified using the PicoGreen fluorescence dye (N.V. Invitrogen SA, BE) which was detected by a Thermo Scientific NanoDrop 3300 spectrophotometer (Thermo Fischer Scientific, USA). The integrity of the DNA was tested through gel electrophoresis. Ten microlitres of each DNA extract and $2 \mu \mathrm{l}$ of loading dye were loaded on a $1.5 \%$ agarose gel. Ten different samples with known DNA concentrations of a Lambda Pstl ( $\lambda /$ Pstl) series were loaded on the same gel in order to estimate the DNA concentration of the samples.

\section{Data analysis}

At four different sampling stages, ten plants were harvested. The mean mass of the fresh material for each vegetative part and cob per sampling time was determined and the standard deviations were calculated over ten samples. These averages were used to calculate the (fresh) vegetative/cob weight ratio. Then, the DNA concentration per lyophilized plant part was determined, the results provided by the spectrophotometer were expressed in $\mathrm{ng} \mathrm{Hl}^{-1}$. These results were converted into the DNA concentration of the total lyophilized plant part. These DNA concentrations were averaged by sampling stage and the vegetative/cob DNA ratio was calculated.

Weight and DNA concentration ratios between endosperm and embryo within a single kernel were determined for three different locations in the cob (top, middle and down) on a total of ten kernels (10 endosperms, 10 embryos). The ratios for the three locations in the cob were also averaged and the standard deviations determined.

The DNA density of each lyophilized plant part was calculated by dividing the overall DNA yield from the lyophilized plant part by the mass of the lyophilized plant part.

The overall GM percentage of one kernel (which corresponds with the GM percentage of grain maize) was calculated by the formula provided by Zhang et al. (2008):

$$
\text { GM ratio grain maize }(X)=1 / 3 F+1 / 2(1-F)
$$

where $F$ represents the DNA ratio endosperm/overall kernel. The DNA content of the overall kernel is determined by the summation of the DNA contents from endosperm and germ DNA, respectively.

The GM percentage for CCM maize is determined by multiplying the GM percentage for grain maize (X) by the DNA content of the total amount of kernels on the cob and subsequently dividing it by the DNA content of one cob as follows:

GM ratio $C C M(Y)=X \times[D N A$ total kernels per cob]/[DNA whole cob] 
The DNA content of all kernels on one cob was defined by multiplying the average DNA content of one kernel by the average total amount of kernels on one cob.

Finally the GM percentage for silage maize is calculated by multiplying the GM percentage for CCM (Y) by the DNA content of the cob and dividing it by the DNA content of the overall plant:

$$
\text { GM ratio silage maize }(Z)=Y \times[D N A \text { whole cob] } /[D N A \text { whole plant }]
$$

The DNA content of the overall plant was defined by the summation of the DNA contents of all different plant parts (vegetative part + cob).

\section{Results}

\section{Plant development at different sampling stages}

Ten maize plants were sampled at four different sampling stages. Each plant was divided in a vegetative part and the cob. The vegetative fraction consists of the stalk without roots, together with the leaves and the husk from the cob. Within each cob, the development stage of the kernels (Ransom et al. 2014) was checked visually. At the first sampling time, the kernel was in the R2 or blister stage where the kernels are white and blister shaped. At the second sampling stage, they evolved into the R3 or milk stage were the inner fluid is milky white due to starch accumulation. During the third sampling stage, the maize kernels had reached the R4 or dough stage where the inner fluid is thickened to a pasty consistency. The final sampling stage was conducted during the R5 or dent stage were the kernels are dented and a small hard layer of starch is formed.

\section{Fresh weight, DNA yield and ratios of vegetative plant parts and cobs}

During the four sampling stages, the weight of the vegetative parts of the plant decreases from $610 \mathrm{~g}$ to $353 \mathrm{~g}$ due to dehydration of the ripening material. The cob weight increases from $124 \mathrm{~g}$ to $226 \mathrm{~g}$. The proportion of the vegetative plant parts reduces in comparison with the cob from 4.92 to 1.56 (Table 1).

Table 1. Mean fresh weights (FW), DNA yields, DNA densities and their ratios between different maize plant parts at different sampling stages (SS). Per sampling stage, a total of 10 plants was taken $(n=10)$ and studied further.

\begin{tabular}{|c|c|c|c|c|c|c|c|c|c|c|c|c|c|c|c|}
\hline \multirow[b]{2}{*}{ SS } & \multicolumn{5}{|c|}{ FW and FW ratios } & \multicolumn{5}{|c|}{ DNA yields and DNA yield ratios } & \multicolumn{5}{|c|}{ DNA densities per FW and density ratios } \\
\hline & $\begin{array}{l}\text { Mean } \\
\text { FW (g) } \\
\text { VE }\end{array}$ & SD & $\begin{array}{l}\text { Mean } \\
\text { FW (g) } \\
\text { CO }\end{array}$ & SD & $\begin{array}{l}\text { Weight } \\
\text { ratio } \\
\text { VE/CO }\end{array}$ & $\begin{array}{l}\text { Mean } \\
\text { DNA } \\
\text { conc. } \\
(\mu \mathrm{g}) \\
\text { VE }\end{array}$ & SD & $\begin{array}{l}\text { Mean } \\
\text { DNA } \\
\text { conc. } \\
\text { ( } \mu \mathrm{g}) \\
\text { CO }\end{array}$ & SD & $\begin{array}{l}\text { DNA } \\
\text { conc. } \\
\text { Ratio } \\
\text { VE/ } \\
\text { CO }\end{array}$ & $\begin{array}{l}\text { Mean } \\
\text { DNA } \\
\text { density } \\
(\mu \mathrm{g} / \mathrm{g}) \\
\mathrm{VE}\end{array}$ & SD & $\begin{array}{l}\text { Mean } \\
\text { DNA } \\
\text { density } \\
(\mu \mathrm{g} / \mathrm{g}) \\
\mathrm{CO}\end{array}$ & SD & $\begin{array}{l}\text { DNA } \\
\text { density } \\
\text { ratio } \\
\text { VE/CO }\end{array}$ \\
\hline S1 & 610 & 113 & 124 & 23 & 4,92 & 4955 & 1968 & 1274 & 314 & 3,89 & 60 & 17 & 73 & 30 & 0,82 \\
\hline S2 & 513 & 74 & 176 & 18 & 2,91 & 7308 & 1838 & 3573 & 1194 & 2,05 & 71 & 19 & 55 & 17 & 1,29 \\
\hline S3 & 423 & 89 & 194 & 32 & 2,18 & 5492 & 1761 & 2937 & 501 & 1,87 & 62 & 12 & 32 & 5 & 1,94 \\
\hline S4 & 353 & 61 & 226 & 24 & 1,56 & 4160 & 1746 & 3645 & 1296 & 1,14 & 46 & 15 & 27 & 9 & 1,70 \\
\hline
\end{tabular}

$\mathrm{VE}=$ vegetative plant parts

$\mathrm{CO}=\mathrm{cob}$

$\mathrm{SD}=$ standard deviation

The next step was to determine the DNA content of the separated plant tissues. Therefore, the separated plant tissues were first lyophilized and DNA was extracted. From the measured DNA concentrations (ng $\mu^{-1}$ ) per mg of material and the mass of the different plant tissues, the mean DNA yield of each plant type was calculated (Table 1).

The DNA yield from vegetative plant parts as well as cob increases between sampling one and two, while afterwards, it decreases between sampling two and four. The DNA content ratio between vegetative parts and the cob decreases from 3.89 to 1.14, these ratios are similar to the weight ratios though they are still slightly lower. From this it can be concluded that the plant parts with potential GM genes (the cob) augment in importance while these without GM genes decrease in importance (Table 1). 


\section{Fresh weight, DNA yield and ratios of different kernel fragments}

In order to follow the evolution of different parts within the kernel, three kernels were removed from ten different cobs. These kernels came from the top (A), the middle (B) and the bottom (C) of the cob. The kernels were taken at sampling stages two and three.

The mean weight of one endosperm is $0.310 \mathrm{~g}$ for sampling stage two and $0.386 \mathrm{~g}$ for sampling stage three (Table 2).

Table 2. Mean $(n=10)$ fresh weights (FW), DNA yields, DNA densities and their ratios between different maize kernel parts at different sampling stages (SS) and over the three different parts. A, B, and C represent top, middle and bottom position in the cob, respectively.

\begin{tabular}{|c|c|c|c|c|c|c|c|c|c|c|c|c|c|c|c|c|}
\hline \multicolumn{7}{|c|}{$\mathrm{FW}$ and $\mathrm{FW}$ ratios } & \multicolumn{5}{|c|}{ DNA yields and DNA yield ratios } & \multicolumn{5}{|c|}{ DNA yields and DNA yield ratios } \\
\hline SS & $\begin{array}{l}\text { Kernel } \\
\text { position } \\
\text { on cob }\end{array}$ & $\begin{array}{l}\text { Mean } \\
\text { FW (g) } \\
\text { EN }\end{array}$ & SD & $\begin{array}{l}\text { Mean } \\
\text { FW (g) } \\
\text { EM }\end{array}$ & SD & $\begin{array}{l}\text { FW } \\
\text { ratio } \\
\text { EN/ } \\
\text { EM }\end{array}$ & $\begin{array}{l}\text { Mean } \\
\text { DNA } \\
\text { conc. } \\
(\mu \mathrm{g}) \\
\text { EN }\end{array}$ & SD & $\begin{array}{l}\text { Mean } \\
\text { DNA } \\
\text { conc. } \\
(\mu \mathrm{g}) \\
\text { EM }\end{array}$ & SD & $\begin{array}{l}\text { DNA } \\
\text { conc. } \\
\text { Ratio } \\
\text { EN/ } \\
\text { EM }\end{array}$ & $\begin{array}{l}\text { Mean } \\
\text { DNA } \\
\text { density } \\
(\mu \mathrm{g} / \mathrm{g}) \\
\text { EN }\end{array}$ & SD & $\begin{array}{l}\text { Mean } \\
\text { DNA } \\
\text { density } \\
(\mu \mathrm{g} / \mathrm{g}) \\
\mathrm{EM}\end{array}$ & SD & $\begin{array}{l}\text { DNA } \\
\text { density } \\
\text { ratio } \\
\text { EN/ } \\
\text { EM }\end{array}$ \\
\hline \multirow[t]{4}{*}{ S2 } & A & 0,31 & 0,064 & 0,02 & 0,0044 & 21,11 & 5,32 & 2,18 & 0,32 & 0,20 & 16,43 & 46,07 & 17,33 & 55,11 & 37,19 & 0,84 \\
\hline & B & 0,31 & 0,045 & 0,02 & 0,0039 & 21,17 & 8,31 & 3,84 & 0,30 & 0,10 & 27,34 & 74,24 & 35,85 & 51,55 & 16,20 & 1,44 \\
\hline & C & 0,31 & 0,051 & 0,02 & 0,0038 & 20,58 & 6,96 & 2,90 & 0,39 & 0,26 & 17,93 & 62,41 & 24,99 & 61,65 & 39,85 & 1,01 \\
\hline & Mean & 0,31 & 0,001 & 0,02 & 0,0002 & 20,96 & 6,86 & 1,49 & 0,34 & 0,04 & 20,57 & 60,91 & 14,15 & 56,10 & 5,12 & 1,10 \\
\hline \multirow[t]{4}{*}{ S3 } & A & 0,39 & 0,068 & 0,03 & 0,0068 & 12,91 & 3,98 & 1,17 & 0,51 & 0,29 & 7,87 & 21,44 & 8,40 & 38,21 & 22,70 & 0,56 \\
\hline & B & 0,38 & 0,029 & 0,03 & 0,0095 & 11,76 & 3,41 & 0,92 & 0,68 & 0,30 & 5,00 & 18,31 & 7,09 & 44,21 & 22,39 & 0,41 \\
\hline & C & 0,40 & 0,067 & 0,03 & 0,0081 & 13,56 & 4,08 & 1,97 & 0,62 & 0,37 & 6,62 & 20,34 & 7,08 & 49,33 & 29,73 & 0,41 \\
\hline & Mean & 0,39 & 0,008 & 0,03 & 0,0018 & 12,74 & 3,82 & 0,36 & 0,60 & 0,09 & 6,49 & 20,03 & 1,59 & 43,92 & 5,57 & 0,46 \\
\hline
\end{tabular}

$\mathrm{EN}=$ endosperm

$\mathrm{EM}=$ embryo

$\mathrm{SD}=$ standard deviation

The weight of the embryo increases from 14.8 to $30.4 \mathrm{mg}$. The ratio endosperm/embryo decreases from 20.96 to 12.74 (Table 2). The importance of the embryo increases during the aging of the kernel, this is a complementary evolution with the dropping importance of the endosperm in the kernel.

The DNA yield from one endosperm varies between 5.32 and $8.31 \mu \mathrm{g}$ for the first sampling (sampling stage 2) and between 3.41 and $4.08 \mu \mathrm{g}$ for the second sampling (sampling stage 3). The mean DNA yield of one endosperm drops from 6.86 to $3.82 \mu \mathrm{g}$ between the first and the second sampling. Unlike the reduction in DNA yield from the endosperm, the embryo increases in DNA yield over time from 0.34 to $0.60 \mu \mathrm{g}$. Similar to these values, the ratio endosperm/embryo drops over time. The endosperm loses importance in favor of the embryo (Table 2). The same evolution is noticeable as for the weight ratios, however the DNA ratio decreases more slowly than the weight ratio though the weight and DNA concentration ratios have the same magnitude at stage two.

\section{DNA quality check}

In order to determine whether the DNA extraction was successful and to estimate the DNA yield, extracted genomic DNA was loaded on a gel and compared with different concentrations of $N / P s t$ DNA. Results are shown in Figure 1.

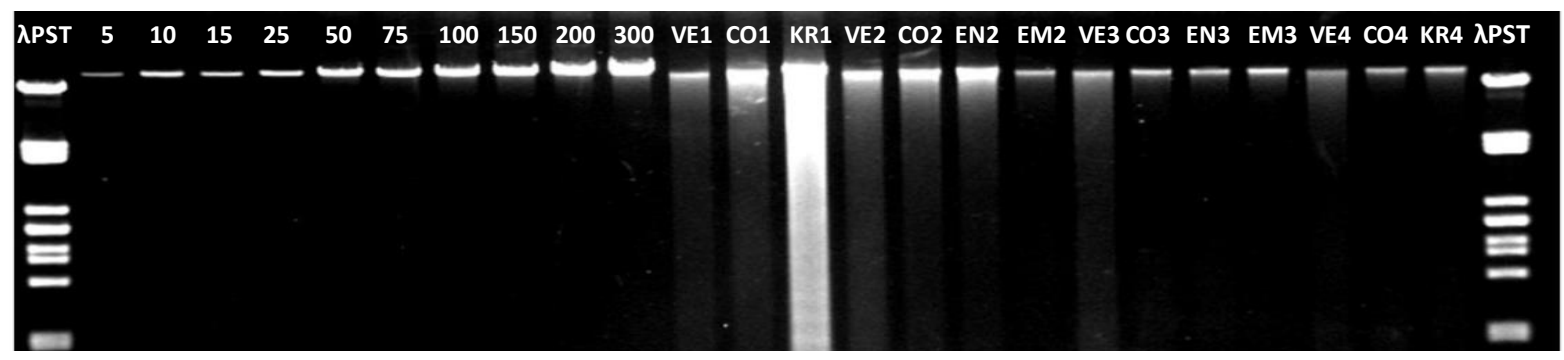

Fig. 1. Estimation of the DNA quantity by loading unknown samples next to Lambda Pstl ( $\lambda /$ Pstl) samples with a known DNA concentration on an agarose gel. Numbers 5 until 300 represent the DNA concentrations from the $\lambda /$ Pstl) series in $n g \mu^{-1}$. $V E=$ vegetative part; $\mathrm{CO}=\mathrm{cob}$; $\mathrm{KR}=$ kernel; $\mathrm{EN}=$ endosperm; $\mathrm{EM}=$ embryo; the numbers 1 to 4 after these codes represent the sampling stages 
The estimated DNA concentrations from the gel were compared with the measured DNA concentrations from the spectrophotometer measurement. For cob, kernel, endosperm and embryo, there is a high DNA yield and the DNA is mostly intact. In general, a high-molecular size band can be detected for all material types while a lower smear of (partially) degraded DNA is sometimes visible, mainly for the vegetative parts (Fig. 1).

The vegetative part of the plant shows good DNA extractability, both measured by spectrophotometer and estimated with gel electrophoresis.

\section{DNA densities for different plant tissues and their ratios}

In order to estimate the DNA density or yield per gram for the different plant textures, the DNA yields are determined from equal weights of tissue (Table 1 and 2). Generally, vegetative plant parts have the highest DNA densities, except for sampling stage 1 where the cob yields more DNA that the vegetative part (Table 1, Fig. 2).

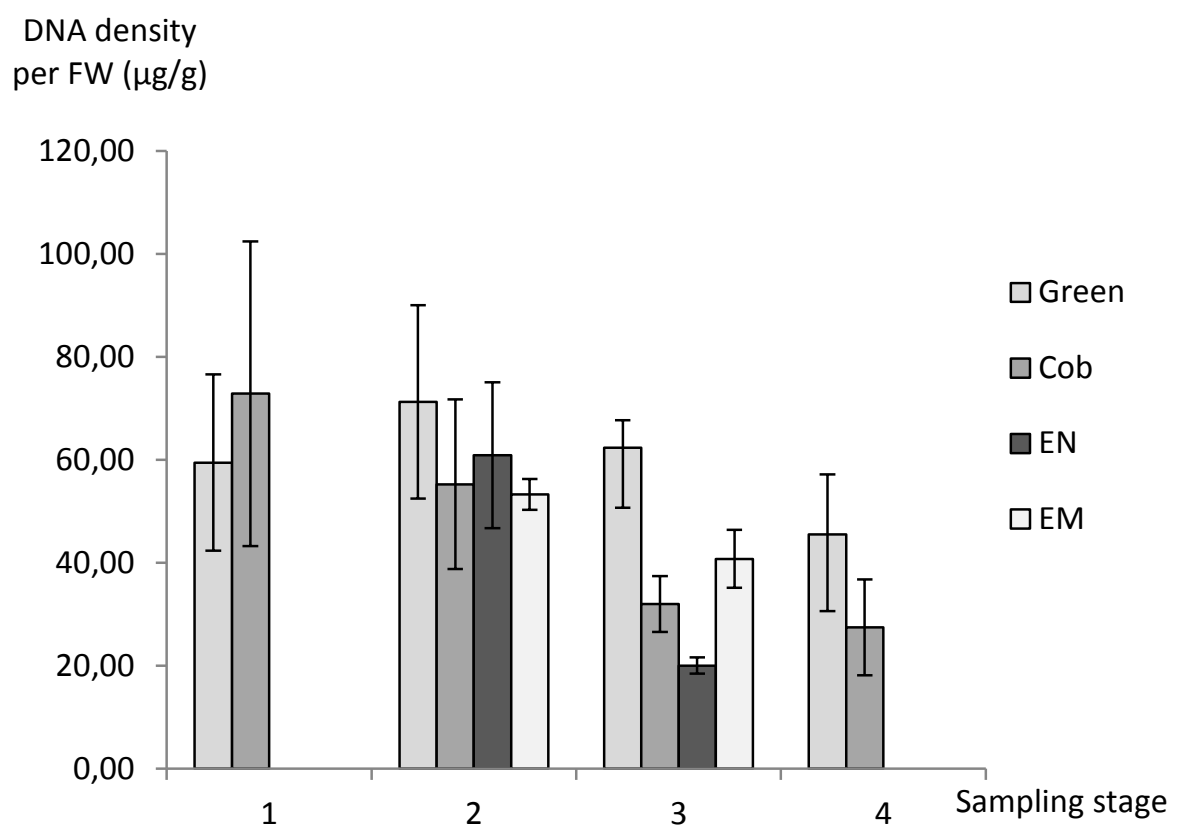

Fig. 2. DNA densities per fresh weigth (FW) of different plant parts at four sampling stages. $\mathrm{EN}=$ Endosperm, EM = Embryo. Vertical bars represent SD over 10 different plants $(n=10)$.

For the second sampling stage, DNA yields for cob, endosperm and embryo are similar. The slightly lower DNA density for the cob and also for the embryo can be explained by the premature development stage of the embryos within the kernels and cob. The vegetative/cob ratio is 1.29 and the endosperm/embryo ratio is 1.10 in sampling stage 2 . These ratios prove the approximately equal DNA yields (Table 1 and 2 ).

The third sampling gives totally different results. Compared to S2, all DNA densities have dropped, while the major decrease is noticeable for the endosperm (from 60.91 at S2 to $20.03 \mu \mathrm{g} \mathrm{g}^{-1}$ at S3, Table 2). This can be explained by the production of other metabolites in the endosperm. The endosperm functions as a storage tissue for carbohydrates and proteins. The ratio of DNA over other substances such as storage polymers will be lower in further sampling stages when the kernels are further developed. Between S2 and S3, the ratio vegetative/cob density has increased from 1.29 to 1.94 due to the decreased extractability of the cob (Table 1). There is a decrease of endosperm/embryo DNA density ratio from 1.10 to 0.46 due to the large differences in DNA extractability between the endosperm and the embryo. Approximately two times more DNA can be extracted from the embryo than from the endosperm (Fig. 1 and 3, Table 2). 


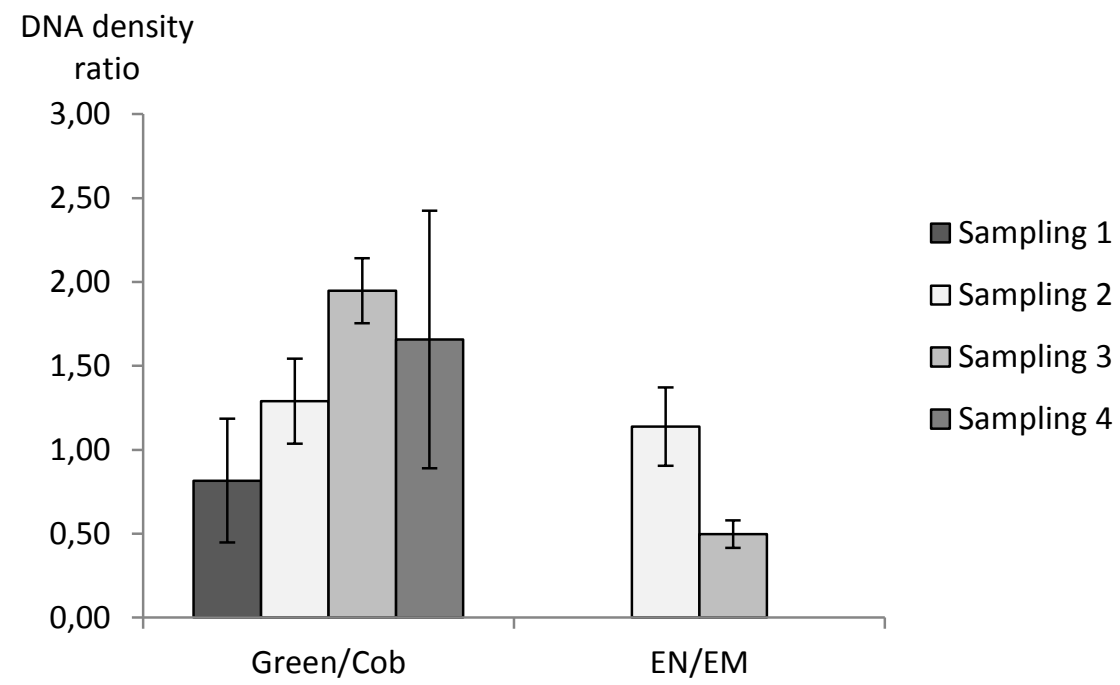

Fig. 3. DNA density ratios of different plant parts at four sampling stages. EN= Endosperm, $\mathrm{EM}=$ Embryo

In order to determine the GM percentage in one kernel, the equation determined by Zhang et al. (2008) is used:

$$
\text { GM ratio }=1 / 3 F+1 / 2(1-F)
$$

where the factor $\mathrm{F}$ represents the relative amount, on a scale from 0 to 1 , of endosperm DNA in the total DNA of a maize kernel. Thus 1-F represents the relative embryo DNA content in a single kernel. Factor $\mathrm{F}$ evolves in time due to the development of the embryo and endosperm at different growth stages (Table 3).

Table 3. Relative fraction (between 0 and 1 ) of endosperm (F) and embryo DNA (1-F) and GM percentages for the three different maize development stages calculated for different maize usages.

\begin{tabular}{cccccc}
\hline & & & $\mathrm{X}$ & $\mathrm{Y}$ & $\mathrm{Z}$ \\
& $\mathrm{F}$ & $1-\mathrm{F}$ & $(\mathrm{GM} \%)$ & $(\mathrm{GM} \%)$ & $(\mathrm{GM} \%)$ \\
\hline S1 & 1 & 0 & 33.3 & 9.46 & 1.61 \\
S2 & 0.95 & 0.049 & 34.12 & 26.79 & 8.79 \\
S3 & 0.86 & 0.14 & 35.59 & 21.23 & 7.4 \\
\hline
\end{tabular}

$\mathrm{X}=$ kernel (corn) maize

$\mathrm{Y}=$ corn cob maize $(\mathrm{CCM})$

$\mathrm{Z}$ = silage maize

The GM ratios of three different stages are calculated. The first stage is based on the assumption that the overall kernel is endosperm because there was no embryo discernible (thus 1-F equals zero). The GM ratio from one kernel times $100 \%$ equals $\mathrm{X}$ or the GM percentage in a single kernel.

There is a slight increase detectable in the relative \% GM genomes in one kernel over time (Table 3). This can be explained by the increasing importance of the embryo DNA in the kernel. Embryo tissue contains relatively more GM genomes than the surrounding endosperm tissue. Nevertheless, the increase is small in comparison to the increase of embryo weight in the kernel.

\section{GM percentage for different maize usages}

It may be assumed that the above calculated GM percentage for one kernel, represents the mean relative GM percentage for all kernels on a maize cob. It thus corresponds to the potential GM percentage of a corn field when it is harvested as grain maize used for food and feed. This percentage can now be extended to other maize usages such as CCM and silage maize. While $X$ represents the GM percentage for grain maize, CCM and silage maize will be determined below as $Y$ and $Z$, respectively. 
For grain maize ( $\mathrm{X}$ values) a slight increase over time is observed, this is described above. For CCM ( $Y$ values) and silage corn ( $Z$ values) there is a strong increase from stage one to stage two: from $9.46 \%$ to $26.78 \%$ for CCM and from $1.61 \%$ to $8.79 \%$ for silage maize. After stage 2 , the values drop slightly (Fig. 4).

$$
\begin{aligned}
& \text { GM\% of grain maize }(X)=\frac{1}{3}\left(\frac{D N A \text { content endosperm }}{D N A \text { content overall kernel }}\right)+\frac{1}{2}\left(1-\frac{D N A \text { content endosperm }}{D N A \text { content overall kernel }}\right) \\
& G M \% \text { of } C C M(Y)=X \times \frac{D N A \text { content kernel }}{D N A \text { content cob }}
\end{aligned}
$$$$
\text { GM\% of silage maize }(Z)=Y \times \frac{D N A \text { content cob }}{D N A \text { content overall plant }}
$$

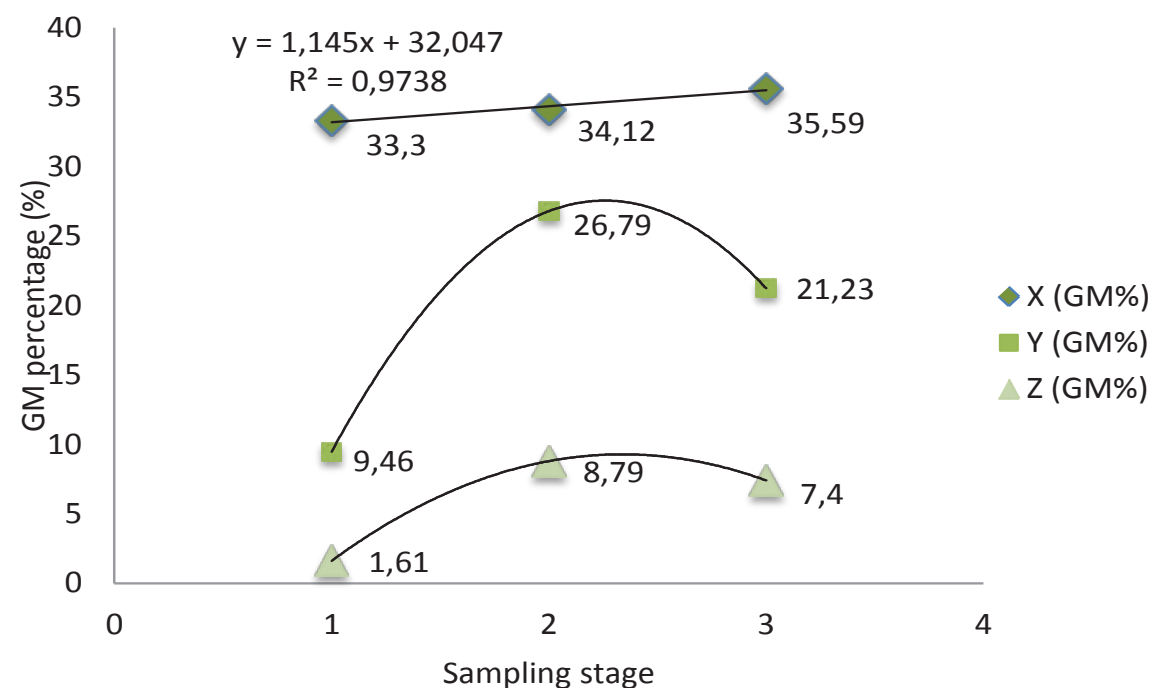

Fig. 4. Expected GM percentage, provided that there is perfect (100\%) cross-pollination with GM maize, on three different sampling stages for different maize usages. $X=$ grain maize, $Y=$ corn cob maize (CCM), Z= silage maize

This decrease in GM content can be explained by a huge difference in DNA yield between the different texture types as described above. Between the various usages there is also a difference in GM content. Logically, grain maize contains the highest GM percentage, as only the kernels contain material from paternal origin. Silage maize has the lowest values, because the highest amounts of maternal tissue are found here, coming from the vegetative plant parts and the center of the cob. The GM DNA content of CCM maize is diluted by the maternal DNA from the spindle. In silage maize, the dilution is greater because the total plant is harvested. The vegetative parts of the plant do not contain GM genes which explains the drop in GM content for this usage.

An important remark is that in these calculations, it is assumed that complete cross-fertilization occurred of the non-GM field by the GM pollen coming from a surrounding field. Our calculations are only valid in the particular case of $100 \%$ out-crossing to neighboring non-GM maize field. This also means that, based on this assumption, a model could be drawn for predicting the expected \% GM (DNA) for lower overall (field- or harvest-based) GM admixture rates. E.g. expect that a $0.9 \% \mathrm{GM}$ cross-contamination at the field level has occurred. In this case, the expected \% GM levels for corn maize expressed at DNA level, will be $33.33 \times 0.9 \%$, $34.12 \times 0.9 \%$ and $35.59 \times 0.9 \%$ respectively. This comes down to $0.3 \%, 0.31 \%$ and $0.32 \%$ GM DNA for the total kernel harvest (corn maize) over the three times respectively, or approx. 0.32\% GM DNA at harvest time. These values will then be lowered to approx. $20 \times 0.9 \%$ or $0.18 \%$ for CCM and approx. $7 \times 0.9 \%$ or $0.063 \%$ for silage maize, respectively, both at harvest time. 


\section{Discussion \\ Evolutions at plant (growth) level}

The general objective of this work was to investigate the influence of sampling (and thus plant growth) stage on GM quantification from different samples, taken at various periods during the growth season of the plant. A first sub-objective was to follow the evolution of different plant parts during the growth season. Generally it can be concluded that plant parts with a relatively high amount of GM genes (embryo in kernel and cob on total plant) augment in importance. Both on weight and DNA concentration level, GM fractions increase during the growth season. This could be expected because pollinated maize plants invest in plant parts which contain their offspring. Microscopic examination of embryo and endosperm tissue of mature kernels has shown that embryos consist of small and dense cells, unlike the cells of endosperm which are large and vacuolated (Schel et al. 1984). Thereby embryo has a major impact on the DNA content of the kernel. Papazova et al. (2005) describes an endosperm/ embryo weight ratio between 23.46 and 12.08 for a fully mature kernel which corresponds with the found ratio of 12.74 in sampling stage three in our experiment.

\section{Evolutions at DNA and \% GM level}

A second sub-objective of this study was to evaluate differences in DNA extractability from different types of maize tissues. For sampling stage two, the observed DNA concentration ratios for the different maize tissues are similar when compared with sampling three.

DNA densities or relative yields (DNA concentration per mg or g of plant tissue material) change during the growth season (Chaouachi et al. 2013). At the second sampling stage equal DNA densities are observed, while the differences are larger at sampling stage three (Table 1 and 2). The explanation can be found in a changing physiological activity, along with strong morphological changes as can be seen in Figure 1. At sampling stage two, all texture types are still developing, however at sampling three the plant is building up carbohydrate reserves in its kernels. This leads to an extractability that is two times higher for the embryo in comparison with the endosperm. These findings are in accordance with the observations of Papazova et al. (2005). Kowles and Phillips (1985) and Schweizer et al. (1995) describe an augmentation of endosperm DNA content during the first development stages of a kernel which declines at the final development stages. Similar results as those on maize described here, have also been obtained for rice by Liu et al. (2010).

Our results show a slight increase in GM percentage over time. The overall GM percentage in grain maize at the final sampling stage can be predicted using samples from an early stage with the following formula:

$$
G M \%=1.145 S+32.047
$$

where S represents the sampling stage. Knowledge on the share of the GM DNA content in other plant textures will allow to predict the relative GM percentage for other maize usages. It should be mentioned that the obtained data and model described here, are only valid for MON810 maize and moreover, for the particular variety of MON810 maize used in this experiment, which was a GM/non-GM hybrid. As a consequence, pollen that is spreading from the GM (MON810) to the non-GM maize field, is only 50\% GM. For other (GM) maize varieties, the data may thus be different.

Another important remark is that in this study $100 \%$ cross-pollination from the GM maize field (GM/non-GM hybrid) to the non-GM maize field has been assumed. Individual plants, which were sampled in the non-GM maize field, were assumed to be $100 \%$ cross-pollinated by the neighbouring GM field. However, it should be taken into account that the probability that each flower in the entire corn field is fertilized by the pollen from the next field is extremely low. Thus a $100 \%$ cross-pollination is very unlikely to occur in real-life.

Taking into consideration both remarks discussed here, it could be concluded that the final GM cross-contamination percentages measured in corn maize of a neighbouring non-GM field would be even lower.

A possible application of the evolution in predicted GM percentage concerns the different uses of maize fields. When a farmer suspects a GM contamination and the results show a GM percentage higher than $0.9 \%$, the farmer could still decide to harvest the lot as CCM or as silage maize instead of corn maize, in order to decrease the GM percentage below the $0.9 \%$ labeling threshold. 


\section{Feasible sampling strategy}

To compose a feasible sampling strategy, it can be interesting to investigate the following methodology in further research. To examine the \% GM contamination level in a non-GM maize field, neighboring a GM maize field, decreasing rates of GM cross-pollination percentage might be expected with increasing distance from the neighbor GM field. Based on empirical testing, different models could be composed to follow the decrease of GM percentage from the border to the center of the field. It is possible to predict the overall GM percentage when a restricted number of cobs are sampled only in the border rows of the field. Each sampling point (a fixed number per meter) represents a certain part of the field. The GM percentage of this part, and subsequently of the whole field can be calculated using the predictive out-crossing models.

\section{Acknowledgements}

The authors thank Annique Staelens, Cindy Merckaert and Mieke Dhondt for their excellent technical assistance.

\section{References}

Chaouachi, M., Berard, A. \& Said, K. 2013. Relative quantification in seed GMO analysis: state of the art and bottlenecks. Transgenic Research 22: 461-476.

EC 2001. Directive 2001/18/EC of the European Parliament and of the Council of 12 March 2001 on the deliberate release into the environment of genetically modified organisms and repealing Council Directive 90/220/EEC. Official Journal of the European Communities L106: 1-38.

EC 2003 a. Regulation (EC) No 1829/2003 of the European Parliament and of the Council of 22 September 2003 on genetically modified food and feed. The Official Journal of the European Union L268: 1-23.

EC 2003 b. Regulation (EC) No 1830/2003 of the European Parliament and of the Council of 22 September 2003 concerning the traceability and labelling of genetically modified organisms and the traceability of food and feed products produced from genetically modified organisms and amending Directive 2001/18/EC. The Official Journal of the European Union L268: 24-28.

EC 2004. Commission Recommendation of 4 October 2004 on technical guidance for sampling and detection of genetically modified organisms as or in products in the contect of regulation (EC) No 1830/2003 (2004/787/EC). The Official Journal of the European Union L348: 18-26.

EC 2010. Commission Recommendation of 13 July 2010 on guidelines for the development of national co-existence measures to avoid the unintended presence of GMOs in conventional and organic crops (2010/C 200/01). The Official Journal of the European Union C 200: 1-5.

Devos, Y., Maeseele, P., Reheul, D., Van Speybroeck, L. \& De Waele, D. 2008. Ethics in the Societal Debate on Genetically Modified Organisms: A (Re)Quest for Sense and Sensibility. Journal of Agricultural and Environmental Ethics 21: 29-61.

Devos, Y., Dillen, K. \& Demont, M. 2014. How can flexibility be integrated into coexistence regulations? A review. Journal of the Science of Food and Agriculture 94:381-387.

Holst-Jensen, A., De Loose, M. \& Van den Eede, G. 2006. Coherence between legal requirements and approaches for detection of genetically modified organisms (GMOs) and their derived products. Journal of Agricultural and Food Chemistry 54: 2799-2809.

Kowles, R.V. \& Phillips, R.L. 1985. DNA amplification patterns in maize endosperm nuclei during kernel development. Proceedings of the National Academies in Science of the United States of America 82: 7010-7014.

Liu, D., Shen, J., Yang, L. \& Zhang, D. 2010. Evaluation of the impacts of different nuclear DNA content in the hull, endosperm, and embryo of rice seeds on GM rice quantification. Journal of Agricultural and Food Chemistry 58: 4582-4587.

Lopes, M.A. \& Larkins, B.A. 1993. Endosperm origin, development, and function. Plant Cell 5: 1383-1399.

Njontie, C., Foueillassar, X., Christov, N.K. \& Hüsken, A. 2011. The impact of GM seed admixture on the non-GM harvest product in maize (Zea mays L.). Euphytica 180: 163-172.

Papazova, N., Malef, A., Degrieck, I., Van Bockstaele, E. \& De Loose, M. 2005. DNA extractability from the maize embryo and endosperm - Relevance to GMO assessment in seed samples. Seed Science and Technology 33: 533-542.

Papazova, N., Taverniers, I., Degrieck, I., Van Bockstaele, E., Joost, H. \& De Loose, M. 2006. Real time polymerase chain reaction (PCR) quantification of T25 maize seeds - influence of the genetic structures in the maize kernel on the quantitative analysis. Seed Science and Technology 34: 307-317.

Piperno, D.R. \& Flannery, K.V. 2001. The earliest archaeological maize (Zea Mays L.) from Highland Mexico: New accelerator mass spectrometry dates and their implications. Proceedings of the National Academies in Science of the United States of America 98: 2101-2103.

Ransom, J., Endres, G.J., Berglund, D.R. \& McWilliams, D.A. 2014. Corn Growth and Management Quick Guide - A1173. North Dakota State University (NDSU). Cited January 2014. Updated 10 March 2014. http://www.ag.ndsu.edu/publications/landing-pages/ crops/corn-growth-and-management-quick-guide-a-1173.

Schel, J.H.N., Kieft H. \& Van Lammeren, A.A.M. 1984. Interactions between embryo and endosperm during early developmental stages of maize caryopses (Zea mays). Canadian Journal of Botany 62: 2842-2853.

Schweizer, L., Yerk-Davis, G.L. Phillips, R.L. Srienc, F. \& Jones, R.J. 1995. Dynamics of maize endosperm development and DNA endoreduplication. Proceedings of the National Academies in Science of the United States of America 92: 7070-7074.

Trifa, Y. \& Zhang, D. 2004. DNA content in embryo and endosperm of maize kernel (Zea Mays L.): Impact on GMO quantification. Journal of Agricultural and Food Chemistry 52: 1044-1048.

Vogler, A., Bertossa, M., Aulinger-Leipner, I. \& Stamp, P. 2010. Wheather effects on cross-pollination in maize. Crop Science 50:713-717. 
Zhang, D., Corlet, A. \& Fouilloux, S. 2008. Impact of genetic structures on haploid genome-based quantification of genetically modified DNA: theoretical considerations, experimental data in MON 810 maize kernels (Zea mays L.) and some practical applications. Transgenic Research 17: 393-402. 